DOI 10.5216/ia.v46i3.65168

\title{
A FORMAÇÃO DE PROFESSORES EM TEMPOS DE ESCALADA DA RACIONALIDADE INSTRUMENTAL
}

\author{
Simone de Magalhães Vieira Barcelos \\ Universidade Estadual de Goiás (UEG), Goiânia, Goiás, Brasil
}

\begin{abstract}
REsumo: O presente artigo tem como finalidade discutir a formação de professores no Brasil considerando a escalada da racionalidade instrumental no campo da educação. A pesquisa é de natureza teórica e parte do entendimento de que há sintonia entre governo federal e as orientações de organismos multilaterais no que diz respeito à elaboração e difusão das políticas nacionais para o campo da educação. Mostramos como a racionalidade técnica se manifesta no campo da educação e como essa intervenção tem se intensificado e acelerado nos últimos anos. Reafirmamos a importância de compreender o presente com vistas a fomentar formas de enfrentamento e resistência ao projeto societal neoliberal em curso.
\end{abstract}

Palavras-chave: Educação. Racionalidade Burguesa. Resistência. Humanização.

\section{INTRODUÇÃO}

Vivemos um contexto profundamente marcado por mudanças nos planos econômico-social, ético-político, cultural e educacional. As mudanças ocorridas no mundo do trabalho e nas relações sociais, conforme Antunes (2001, 2018, 2020), puseram em curso novas demandas e grandes desafios, sobretudo para o campo social. O desenvolvimento social e econômico, em suas diferentes etapas, reclama para si projetos pedagógicos que atendam, ainda que parcialmente, as demandas do modo de produção capitalista. A atual etapa do modo de produção capitalista (globalização) da economia impõe, necessariamente, diferentes estratégias; as quais apresentam, em quase sua totalidade, amplo poder de alcance sobre todas as esferas da sociedade. Dourado (2018) mostra a correlação de forças, as disputas políticas travadas em torno do reordenamento das relações sociais, sobretudo no campo da educação. A formação de professores é um campo de disputas de concepções que se articulam com questões mais amplas, principalmente a dimensão econômica.

A centralidade deste trabalho é discutir as condições objetivas em que as políticas de formação de professores têm sido pensadas e materializadas em âmbito nacional. O intuito é de, a partir da análise dessas condições, perceber seus limites e possibilidades numa visão prospectiva de resistência e de luta pela educação pública e pela democracia. Para tanto, buscamos pensar questões como: a concepção de educação, organismos indutores das políticas educacionais no Brasil e a presença da racionalidade instrumental nas políticas para formação de professores. 


\section{DESENVOLVIMENTO}

O contexto internacional dos países industrializados tem sido referência tanto para observações quanto para o estabelecimento de estratégias políticas e econômicas, com vistas à manutenção e ampliação do modelo de produção capitalista, comportando em seu interior as mais variadas formas de contradições, geradas a partir das relações sociais próprias deste modelo de produção. Desconsiderando significativas particularidades dos países em desenvolvimento, a política neoliberal propõe orientações e estratégias para as diferentes esferas da realidade concreta daqueles países, dentre elas o campo da educação. Isto não é algo isolado, pelo contrário, é um movimento que alcança quase que a totalidade dos países.

Essa realidade não pode ser pensada sem que o neoliberalismo seja considerado como responsável por parte significativa de tais mudanças. $O$ neoliberalismo, como argumenta Harvey (2008), está alicerçado nos fundamentos do Liberalismo clássico, está vinculado a uma racionalidade marcada pelo pensamento conservador. No contexto nacional, especialmente nas quatro últimas décadas, essa racionalidade tem se espraiado, sobretudo no campo da educação, por meio das políticas educacionais.

A reflexão sobre essas questões exige que o neoliberalismo seja considerado naquilo que o constitui e ao mesmo tempo o que ele expressa. Ele é uma política econômica que assume o mercado como ponto de partida e de chegada em seu projeto societal, quer dizer, põe a condição, a existência humana em segundo plano. Enquanto política econômica "manteve e mantêm uma campanha inexorável contra tudo o que possa parecer "social", de modo a priorizar tudo o que possa ser ou parecer econômico" (IANNI, 2004, p. 334). Assim, na sociedade industrial, a economia pensa e, na maioria das vezes, decide o modelo de existência. O projeto neoliberal vislumbra a expansão e a continuidade do capitalismo e é nesse sentido que Mészaros (2005) traz à luz o caráter destrutivo do capital. Ancorado nos estudos de Mészaros, Antunes $(2018,2020)$ analisa o trabalho, inclusive no contexto da pandemia, e assevera que a ampliação e aceleração do processo de precarização do trabalho, inclusive o trabalho docente, confirma a letalidade do capital em vista de tudo que é social. Tudo isso se dá sob a égide do projeto neoliberal, num sofisticado e avançado entrecruzamento da ciência e da tecnologia.

A materialização dessa política econômica implica acentuado grau de ampliação e aprofundamento da desigualdade econômica, social e política entre os seres humanos. A reflexão sobre o neoliberalismo deve tomar os contextos mundial e local como referência, com vistas a avançar nas análises e na formulação de possíveis formas de enfrentamento e resistência a esse projeto que tem como finalidade a organização da existência humana segundo os interesses do capital. Um aspecto fundamental a considerar nesse jogo perverso é que ele se dá num movimento de continuidades e descontinuidades. Há algo que permanece, algo que lhe é constitutivo: a vinculação com o projeto burguês e a lógica que o orienta. Dordot e Laval (2016) asseveram que o neoliberalismo é uma nova forma de razão e a escalada dessa 
racionalidade instrumental está em curso na contemporaneidade. Trata-se de uma razão que elege o mercado, a dimensão econômica em detrimento do ser humano, da dimensão social. Uma nova razão para a velha questão de classe.

Frigotto $(1999,2011)$, Mészaros (2005), dentre outros, mostram que não há nada novo, a questão de classe é a gênese da disputa do projeto societal entre burguesia e proletariado e essa disputa se dá também no campo educativo. Desse modo, no que concerne a formação de professores, compreender o presente parece ser um dos maiores desafios para empreender algum enfrentamento e resistência. $O$ exame sobre o tipo de racionalidade que tem governado ou desgovernado o mundo, é tarefa da qual não podemos nos esquivar. Nesse sentido, retomar o conceito de racionalidade instrumental, elaborado por Horkheimer (1976), bem como as análises de Adorno e Horkheimer (1991) sobre esse conceito, parece ser tarefa indispensável para pensar as questões no campo da educação e da formação.

Na presente reflexão, o conceito de racionalidade instrumental é considerado à luz do conceito razão instrumental formulado por Adorno e Horkheimer (1991) e Horkheimer (1976) nas obras Dialética do esclarecimento: fragmentos filosóficos e Eclipse da Razão, respectivamente. Em suas análises, os autores mostram que, por meio da razão instrumental, a cultura administrada orienta e ordena a existência humana em direção ao conformismo e a heteronomia, buscando a conservação e a expansão da sociedade industrial. Esse movimento realizado pela cultura administrada confere à marcha histórica ares de determinação, embora se trate da condição do tempo presente. Desse modo, o que se conserva na sociedade industrial é exatamente o uso da razão esvaziada de sua dimensão objetiva.

Horkheimer (1976), ao asseverar que a razão instrumental é constitutiva da cultura na sociedade industrial, põe em questão não apenas a redução das possibilidades do exercício do pensamento, desvela, desde aquele contexto do pósguerra, a escalada do conhecimento técnico e o cultivo da desumanização. Esse cultivo prospera graças à individualização, à domesticação, à alienação, à reificação do homem.

Assim, reconhecer a escalada da racionalidade instrumental parece um passo importante, pois permite trazer à memória que a sociedade industrial, por meio da cultura administrada, "está se afundando em uma nova espécie de barbárie" (ADORNO; HORKHEIMER, 1991). A racionalidade instrumental decorre da razão, que, em sua condição histórica, esvaziada de reflexão, tornou-se um contínuo exercício de retorno ao pensamento mítico. A razão abriu mão da reflexão, do exame rigoroso das questões e dos conceitos. Contenta-se em realizar-se enquanto técnica, e isso foi possível uma vez que, "no trajeto para a ciência moderna, os homens renunciaram ao sentido e substituíram o conceito pela fórmula, a causa pela regra e pela probabilidade". A gravidade das implicações do abandono do conceito são trazidas por Adorno e Horkheimer para o centro do debate filosófico. Mas, o que é o conceito? É o "produto do pensamento dialético no qual cada coisa só é o que ela é tornando-se aquilo que ela não é" (ADORNO; HORKHEIMER, 1991, p. 21).

A razão instrumental produz "a alienação dos homens com relação aos objetos dominados; com a coisificação do espírito, as próprias relações dos homens foram enfeitiçadas, inclusive as relações de cada indivíduo consigo mesmo" e se "o animismo havia dotado a coisa de uma alma, o industrialismo coisifica as almas" (ADORNO; 
HORKHEIMER, 1991, p. 40). Assim, ancorados no conceito de razão instrumental, parece correto problematizar em que medida as políticas públicas para o campo da formação de professores corroboram o projeto de sociedade em vista da continuidade e expansão do sistema existente.

Desse modo, é preciso compreender porque o conceito de educação é central para o neoliberalismo, assim como foi para o Liberalismo clássico, como tão bem assinala Harvey (2008). Essa centralidade decorre do entrelaçamento da educação com a questão do Capital Humano. Frigotto (1999) e Mészaros (2005) mostram que, dentre os aspectos constitutivos do jogo político e das disputas no campo da educação, o que se conserva é a ideia de preparar o homem para atingir fins pré-determinados pelo capital. Evangelista (1997) analisa a sintonia, a articulação e a consonância entre o projeto de reestruturação do capital, os organismos multilaterais e os governos de países em desenvolvimento via políticas públicas destinadas ao campo da educação. Tais análises asseveram que a racionalidade instrumental combate veementemente a ideia de formação humana em sentido amplo e, ao combatê-la, busca substituí-la pela ideia de preparar para o trabalho. Há sempre a intenção e a necessidade de circunscrever a formação às necessidades e interesses do capital. Essa ideia instrumental de formação é a mesma que ataca e limita o pensamento e o uso da razão. Se consideramos a intencionalidade de ordenação e nivelamento presente em tais políticas, os termos preparação e treinamento parecem fazer mais sentido que o termo formação.

Mészaros (2005) evidencia que no campo social as coisas não se resolvem, mas se desenvolvem. Reconhecer esse movimento histórico sinaliza que toda forma de enfrentamento e resistência ao neoliberalismo passa, necessariamente, pela atitude filosófica de busca pelo conhecimento das coisas, supõe o retorno ao conceito e também ao debate e exercício da liberdade do pensamento. A tensão, as disputas nos campos político, econômico e da educação, o movimento de correlação de forças e interesses que constituem essa realidade que buscamos desvendar se conserva. Ianni (2004) mostra como o projeto neoliberal é perverso e violento, sobretudo porque tem em vistas a universalização, a padronização da forma de produção da vida e da existência humana. Daí a necessidade de se opor aos reducionismos que se manifestam de diferentes formas, explicita ou implicitamente, nas políticas públicas para formação de professores, principalmente a crescente reprodução e instauração do irracionalismo, da racionalidade instrumental, do ataque ao intelectualismo comum nos dias atuais.

Pensar as políticas para formação docente exige a compreensão dos principais elementos da reestruturação produtiva do capitalismo: processo de globalização/mundialização; revolução técnico-científica; projeto neoliberal em curso. Esse projeto põe em xeque o papel do Estado no que se refere às políticas sociais e defende as teses do Estado mínimo: flexibilização, desregulamentação e privatização. A forma flexibilizada de acumulação capitalista deu origem a inúmeras consequências sociais que fragilizam a condição humana de modo assustador, pois "criaram, portanto, uma classe trabalhadora mais heterogênea, mais fragmentada e mais complexificada" (ANTUNES, 2001, p. 23). Em suas recentes análises, considerando o contexto da Pandemia da Covid-19, Antunes (2020) denuncia a ampliação e o aprofundamento da 
precarização das condições de vida da classe trabalhadora, sobretudo daqueles que estão à margem do trabalho regulamentado. $O$ autor lembra que a pandemia não causou essa precarização, no entanto, a intensificou. $O$ fato é que a pandemia, de certo modo, evidenciou a questão das desigualdades sociais. lanni (2004) mostra que são exatamente as desigualdades sociais que criam as condições para que a política neoliberal exerça uma espécie de terrorismo e violência contra as camadas populares.

Entendemos que pôr as políticas para formação docente no centro do debate é uma forma de enfrentamento e resistência, e essa tarefa pressupõe clareza quanto à concepção de educação. Neste artigo, educação é entendida como prática social, atividade que vai além da escola e, portanto, se faz nos mais diferentes lugares e situações da realidade concreta. Entender a educação enquanto prática social significa reconhecê-la como produção cultural, busca de conhecimento, crenças e valores historicamente construídos. Assim, reconhecemos com Brandão (1988) e Gramsci (1978, 1985) que a educação é possibilidade de transformação dos sujeitos situados historicamente e não somente domesticação e produção de heteronomia. Ela é, a um só tempo, movimento e ordem, sistema e contestação, é atividade humana que se abre não apenas no sentido de conhecer e de compreender a história, mas, acima de tudo, de transformá-la. Gramsci (1985) desvela a existência de um projeto de pretensão hegemônica da sociedade industrial. Essa afirmação nos provoca a considerar a importância da atitude política de resistência e de enfrentamento da questão, por mais complexa que ela seja e ainda que se apresente como algo inexorável.

\section{REFLEXÕES SOBRE POLITICAS PÚBLICAS PARA O CAMPO DA EDUCAÇÃO}

A despeito do que discutimos até aqui, reconhecemos que a concepção de educação que tem orientado as políticas nacionais para educação em geral e para a formação de professores em particular vai na direção oposta à concepção em que nossas reflexões estão ancoradas. Hypolito (2019) argumenta que a concepção reducionista e instrumental de educação e de formação que perpassa os organismos multilaterais indutores das políticas educacionais em âmbito mundial e nacional tem sido implementada cada vez mais no campo da educação em escala mundial e nacional. Segundo o autor, a sintonia entre as orientações de organismos multilaterais e o governo pode ser identificada por meio de uma agenda global que, por diferentes vias e variadas estratégias, vai se materializando no contexto local.

Pensar as políticas para formação de professores nas últimas décadas supõe considerar, por exemplo, que os organismos internacionais, como Organização das Nações Unidas para Educação, Ciência e Cultura/ UNESCO, Fundo Monetário Internacional/FMI, Banco Mundial/BM, indutores de tais políticas, são seus legítimos representantes, argumenta Evangelista $(1999,1997)$. Segundo a autora, o BM é o maior indutor de políticas públicas nos países em desenvolvimento.

A UNESCO promoveu dois eventos grandiosos na última década do século XX: a Conferência Mundial em Jomtien, em 1990, e organizou a Comissão Internacional sobre Educação para o século XXI. Esses eventos são extremamente significativos para compreender as políticas educacionais do Brasil a partir da década de 1990. Havia ali uma racionalidade instrumental, ou seja, uma intencionalidade no sentido de propor 
soluções para conflitos que eclodiam na sociedade moderna em âmbito mundial, dentre eles "crise moral", "violência e da criminalidade", "desencanto dos cidadãos pela coisa pública" e "crise nas políticas sociais", segundo Delors (1998). Vemos que a racionalidade instrumental faz crer que, no campo social, as coisas se resolvem. Nesses eventos, o movimento em torno das políticas públicas teve o intuito de encontrar formas de conter o risco desenfreado do aumento da miséria e da marginalização nos países em desenvolvimento e, de certa forma, nos países desenvolvidos. No entanto, é preciso registrar que o crescente aumento da miséria e da violência seria um desdobramento das estratégias perversas adotadas para a reestruturação do modelo de produção capitalista.

A Conferência de Jomtien (1990) formulou e defendeu "educação básica para todos", preconizou a expansão/universalização da educação básica, contudo, houve um silêncio em relação à questão da qualidade da educação. Em 1993, a Comissão sobre educação para o século XXI, apesar de tomar como referência para seus trabalhos a bandeira levantada em Jomtien, apresentou e defendeu a ideia de "educação ao longo de toda a vida", uma educação que deve aproveitar todas as oportunidades oferecidas pela sociedade. Essa proposta, formalizada e difundida por Delors (1988), também busca atender aos imperativos do capital. O que está em pauta, segundo Torres (2001), é uma formação para a adaptação, uma educação que é chamada a desempenhar essencialmente o papel de apaziguadora de conflitos provocados pelas desigualdades sociais no mundo capitalista. Enfatiza-se um modelo de educação flexível e desregulamentado, num tipo de aprendizagem orientado para o saber fazer, para a execução de tarefas pré-determinadas.

A atual Lei de Diretrizes e Bases da Educação Nacional - LDB 9.394/96 foi regulamentada num contexto em que o debate e as discussões entre educadores e a sociedade civil, de um modo geral, mostrou-se significativo, representativo e democrático. Os educadores mostraram-se preocupados e engajados com a questão diretamente relacionada à sua profissão. A Associação Nacional pela Formação dos Professores da Educação - ANFOPE demonstrou, por meio de seus representantes, profundo interesse em participar do processo de discussões e debates quando da elaboração da LDB. Essa foi "a primeira lei que viveu um amplo processo de discussão para que se chegasse a um consenso entre diferentes associações educativas e representantes civis de um modo geral" (TOSCHI, 1997, p. 8), mas o processo democrático foi rechaçado e relegado pelas autoridades competentes, ou seja, os deputados federais que votaram na finalização de seu doloroso processo no dia $17 / 12 / 96$.

Na atual LDB, o título VI, denominado "Dos profissionais da educação", é destinado à formação de professores. Melo (1999) mostrou à época que esse título foi um dos mais reduzidos, já sinalizando uma lógica instrumental em relação à formação de professores. Essa mesma lei sinaliza flexibilização quanto ao locus da formação, abrindo a possibilidade para que a formação de professores aconteça nos Institutos Superiores de Educação', art. 62 da LDB, como assevera Aguiar (1997), é claro o descaso com a questão da qualidade da formação de professores e uma adesão declarada a um 
projeto de educação e de formação que prioriza a prática em detrimento da teoria.

Questões dessa natureza ajudam a entender com maior clareza o significado da transferência de responsabilidade pela formação de professores, ou seja, das Universidades para os Institutos Superiores de Educação. Como abrir mão de uma formação de professores oferecida em cursos de Pedagogia, considerando a estrutura das universidades e a própria trajetória histórica do curso e transferi-la para Institutos desprovidos de condições básicas? O surgimento dos Institutos, enquanto espaço para formação de professores, foi pautado pelo autoritarismo e pelo distanciamento entre as aspirações dos educadores e sociedade civil, e as reais intenções do governo federal sobre esta questão. As disputas sobre o locus da formação estão sempre em questão num contexto marcado pela escalada da racionalidade instrumental, isso não podemos ignorar. No contexto atual, a iniciativa privada tem forte presença no campo da formação de professores e essa presença se materializa por meio das filantropias privadas, dos institutos, das fundações, das parcerias público-privado, dentre outras. Tais instituições não atuam apenas na formação, são, por assim dizer, uma das mais expressivas fontes de elaboração e oferta de material pedagógico e oferta de cursos, sobretudo para a educação pública. Hypolito (2019) argumenta que a influência dos organismos internacionais e das instituições privadas é cada vez mais presente na educação pública em âmbito nacional e destaca que a sintonia entre eles está fundamentada na adesão ao projeto neoliberal de formação, tão bem delineado na BNCC e na BNC.

Essas e outras definições legais que continuaram surgindo permitem perceber a concepção de formação que orienta e sustenta as políticas para a formação de professores da educação básica no Brasil. É nesse ponto que chamamos atenção para o que permanece, quer dizer, é perceptível a influência de uma concepção que pretende uma formação direcionada para o trabalho e, para tanto, apresenta um contorno geral marcado pela ênfase na necessidade da técnica operacional que transformaria, grosso modo, o professor num mero executor de tarefas.

Da forma como foi elaborada, a atual LDB priorizou a formação em serviço, uma modalidade que atende, em larga medida, a lógica neoliberal recomendada pelo BM. Trata-se, sobretudo, da banalização da formação de professores, pois privilegia uma modalidade de formação desvinculada da pesquisa e da produção do conhecimento, dificultando, na maioria das vezes, a possibilidade de aprofundamento nos estudos e de exercerem a condição de sujeitos no sentido que Gramsci (1978) sinaliza.

A concepção de educação e de formação presente nas políticas de formação de professores desde a década de 1990, aproxima-se, quase em sua totalidade, de uma proposta de formação cujo horizonte possível e desejável é o aligeiramento via rebaixamento das exigências e das condições estruturais dessa formação. Essa concepção supõe a existência de um professor prático, apto a solucionar problemas cotidianos que lhe são apresentados sem, contudo, investigá-los em suas condições concretas. Essa concepção instrumental de formação, direta ou indiretamente, se conserva no campo da educação, perpassa as disputas que se travam no contexto mais amplo em âmbito nacional. Há, sempre, uma intencionalidade no sentido de deslocamento da relação teoria e prática, intentam instaurar a predominância da prática na formação inicial e continuada de professores. A ameaça de esvaziamento e controle 
do trabalho docente tem sido uma constante. Graças às avaliações estandardizadas, os organismos internacionais, por meio de seus representantes locais, induzem políticas, determinam metas, conteúdos e estratégias de acordo com interesses e necessidades do mercado. Instituições internacionais, como a Organização dos Estados Americanos/OEA, o Banco Interamericano de Desenvolvimento/BID, o Programa das Nações Unidas para o Desenvolvimento/PNUD, o Programa de Reformas Educacionais da América Latina e Caribe/Preal, a Comunidade Europeia/CE, surgem como agentes ativos em defesa da homogeneização, do nivelamento e padronização da educação e da formação.

A legislação nacional induz e propicia a proliferação desenfreada de cursos de baixa qualidade em instituições privadas que se beneficiam da ausência de uma política pública que favoreça a ampliação do número de vagas nas universidades públicas. Antes, como argumenta (BRZEZINSKI, 1999), consiste numa política de formação que favorece a prática ou a cultura da certificação. No contexto nacional, tem prevalecido no campo da formação de professores uma assimilação expressiva das orientações internacionais por parte do governo brasileiro, o que está refletido claramente não apenas na LDB 9.394/96, mas na Base Nacional Comum Curricular/BNCC/CNE/2019 e a atual proposta de Diretrizes Nacionais Curriculares Para a Formação de Professores da Educação Básica que está em discussão no referido Conselho. A BNCC/2019, documento discutido e problematizado pelo campo da educação em âmbito nacional, sobretudo pelo movimento de educadores e representantes das entidades científicas, no nosso entendimento, expressa sintonia entre governo federal e as orientações de organismos multilaterais, com um projeto neoliberal de sociedade, nos termos explicitados por lanni (2004).

A BNCC CNE/2019 vai na contramão do que está disposto na Resolução CNE n.02/2015, tem ares de "canto da Sereia", não há muito o que apreender nas entrelinhas, em outras palavras, o projeto de formação que se anuncia sinaliza estreita vinculação com o projeto neoliberal de reestruturação produtiva. O rico e extenso debate que tem ocorrido em diferentes espaços em torno da BNCC e BNC deixa claro que não se trata meramente da formação de professores, mas de um projeto de sociedade, de humanidade, de existência humana, um projeto decorrente da racionalidade instrumental que tende a imperar na sociedade administrada.

Insistimos na ideia de que no projeto societal neoliberal há algo que se conserva e, no que refere à formação de professores, o que tem sido conservado parece ser a negação da liberdade de pensamento, o uso da razão, a possibilidade da formação humana em sentido amplo. Desde as Diretrizes Nacionais para Formação de Professores da Educação Básica de 2001, a ideia de formação já se apresenta bastante limitada e empobrecida. Os eixos centrais desse documento eram as ideias de Competência, Flexibilização e Qualidade. A ideia de Competência retorna na BNCC e na BNC, mas há um aspecto que merece nossa atenção, é um projeto ambicioso que se materializa de forma muito particular, estrutural, intenta mudar tanto a formação de professores quanto imprimir um reordenamento curricular na educação básica, abarcando, inclusive a Educação Infantil. Maria Helena Guimarães Castro (2018), atual presidente do Conselho Nacional de Educação, organizou o livro Educação em pauta: uma agenda para o país. A obra guarda estreita sintonia com a BNCC e apresenta propostas para resolução de 
problemas na Educação Infantil. Assim, desde a primeira etapa da educação básica, o que se conserva é um projeto de formação com vistas à preparação para o trabalho, representando grande risco de desqualificação e banalização da formação. O discurso da qualidade retorna, mas continua esvaziado de sentido, pois como argumenta Gentili (1995, p. 177), não existe "qualidade" com dualidade social. [...] "qualidade" para poucos não é qualidade, é privilégio". O discurso oficial ataca a Escola, a Universidade, a Ciência e deixa no ar o anúncio da "crise" no campo da formação. Miranda (2016) chama a atenção para esse discurso neoliberal que anuncia a "crise" e logo em seguida apresenta um conjunto de estratégias para superação da mesma. É um discurso que desqualifica o trabalho do professor e a formação oferecida na universidade pública. Os efeitos e desdobramentos do neoliberalismo no campo da educação manifestam-se mais claramente na formulação e implementação de políticas públicas que, em sua maioria, sinalizam a privatização da educação com ênfase num amplo e articulado sistema de avaliação que alcança os diferentes níveis de ensino em âmbito nacional. Assim, a formação desejada deve preparar para o mercado e para o êxito nas avaliações sistêmicas. Se considerarmos a análise de Adorno (1995) sobre a questão da educação e da formação, tal educação pode ser denominada deformação, pois é esvaziada de sentido e da possibilidade de propiciar experiências intelectuais aos que dela participam.

Os embates travados entre os diferentes movimentos representativos dos educadores e o mundo oficial seriam expressões genuínas de respeito à cidadania. No entanto, é preciso constatar o lado cruel e real desses embates. Na maioria das situações e divergências, não se trata de respeito à cidadania e sim de disputa pelo poder, por parte das "elites políticas do mundo oficial; que desejam manter sua autoridade a qualquer preço" (BRZEZINSKI, 1999, p. 100). Um poder que tem suas raízes firmadas na realidade dos países industrializados, que utilizam seu poder econômico como instrumento de opressão sobre os países em desenvolvimento. Quando os embates acontecem, disputas estão em jogo, o que vão decidir e para quê. De certa forma, quase não há o que decidir no que se refere ao mundo oficial, há sim o que anunciar, e a preocupação então seria qual a melhor estratégia e hora para fazê-lo.

No atual contexto, as forças civis veem-se enfraquecidas, de certa maneira desmoralizadas, desconsideradas e, quando a legislação é a expressão do autoritarismo do governo e da sintonia deste com as orientações de organismos multilaterais, à primeira vista, parece não ter muito o fazer, a não ser recobrar as forças e procurar dentre as imposições e mecanismos de adequação ao ajuste exigido pela reestruturação do capital, novos caminhos e formas fecundas de enfrentamento, que assegurem, nas mais variadas situações do processo de formação de professores, um projeto de educação que contemple a formação humana em sentido amplo e crítico em todos os níveis e modalidades de ensino. Como diria Guimarães Rosa, em Grande sertão: veredas, é preciso coragem para enfrentar, lutar e resistir às vicissitudes.

Cury (2000) argumenta que conhecer e compreender as políticas públicas e a legislação educacionais é imprescindível, mas não é suficiente. Resistir, lutar, assumir e exercitar a coragem supõe ainda perceber os limites e possibilidades de tais políticas e, a partir dessa percepção, promover a elaboração e o desenvolvimento de projetos e ações que tenham como norte a luta por uma educação e formação com qualidade social. Resistir à racionalidade instrumental supõe o reconhecimento da importância de um 
projeto formativo que vislumbre a formação do homem, a melhoria da humanidade, a construção de um projeto de sociedade mais aberto a realização de uma existência mais justa, fraterna e ética.

\section{CONSIDERAÇÕES FINAIS}

As políticas educacionais para formação de professores nas últimas décadas são mais bem compreendidas a partir da necessária contextualização das contingências históricas e econômicas que compõem a realidade atual e as transformações nelas ocorridas. Por isso, ao longo do texto, procuramos nos ater a elementos constitutivos do processo de elaboração, regulamentação e alguns desdobramentos de tais políticas no campo da educação e da formação. Nossa análise procurou se manter fiel a uma concepção crítica de educação, com a finalidade de compreender a racionalidade instrumental e seus desdobramentos nas políticas de formação de professores em âmbito nacional.

Vimos que a sintonia entre as políticas para formação docente e as orientações dos organismos multilaterais é constante e que esse é um campo de disputas, de concepção: de educação, de docência, de formação, de mundo, disputas que se articulam com questões mais amplas, sobretudo com a dimensão econômica. Não há como negar a presença da racionalidade instrumental nas políticas para o campo da educação em geral e para a formação de professores em particular. Dentre as principais consequências dessas políticas destacamos: o aligeiramento na formação; a ênfase na modalidade de formação a distância e na formação em serviço; expansão de cursos de curta duração e com qualidade duvidosa; ênfase no ensino em detrimento da pesquisa; ênfase na prática em detrimento da teoria, precarização e flexibilização do trabalho docente e, no contexto da pandemia, somos testemunhas de um processo de intensificação da flexibilização na relação público-privado.

Não há porque nos assustarmos com o atual contexto, não há nada de novo nele, a não ser a intensificação da precarização do trabalho em geral e do trabalho docente em particular. Isso deve provocar nossa inteligência no sentido de nos dedicarmos ao estudo, à busca do conhecimento sobre a realidade que se apresenta como algo dado e pronto. O trabalho do professor é, sobretudo, o de desvelar aquilo que está encoberto à sua volta. A resistência não se realiza sob eclipse e nem se constitui no isolamento, antes, supõe reflexão, decisão, ações individuais e coletivas.

Vimos que, para além da noção de competência, anunciada direta o indiretamente nas BNCC e na BNC, da defesa pelo ensino de aprendizagens essenciais, há que insistir numa concepção de formação inicial e continuada que considere as dimensões pedagógica, técnica, ética, política, dimensões constitutivas da formação e da existência humana.

Pensar as implicações filosóficas das políticas públicas para o campo da formação parece ser tarefa que não podemos nos furtar a realizar, pois o ponto imperativo da nossa condição histórica é a reflexão. Compreender o discurso da ação pela ação, da prática pela prática e resistir a ele é uma atitude filosófica, é participação política que se levanta contra a racionalidade instrumental que tende a prevalecer em 
BARCELOS, S. M. V.

nossos dias.

Artigo recebido em: 20/08/2020

Aprovado para publicação em: 30/12/2020

\section{TEACHER TRAINING IN ESCALATING TIMES OF INSTRUMENTAL RATIONALITY}

ABSTRACT: The purpose of this article is to discuss teacher training in Brazil considering the escalation of instrumental rationality in the field of education. The research is of a theoretical nature and is based on the understanding that there is harmony between the federal government and the guidelines of multilateral organizations regarding the development and dissemination of national policies in the field of education. We show how technical rationality manifests itself in the field of education and how this intervention has intensified and accelerated in recent years. We reaffirm the importance of understanding the present with a view to fostering forms of confrontation and resistance to the ongoing neoliberal societal project.

KEYWORDS: Education. Burgeois Racionality. Resistence. Humanization.

\section{LA FORMACIÓN DE PROFESORES EN TIEMPOS DE ESCALADA DE LA RAZÓN INSTRUMENTAL}

RESUMEN: Este artículo tiene como finalidad discutir la formación académica de profesores en Brasil considerando el aumento de la racionalidad instrumental en el campo de la educación. La investigación es de carácter teórico y parte del entendimiento de que, en larga escala, hay sintonía entre el gobierno federal y las directrices de organizaciones multilaterales en lo que se refiere al proceso de elaboración y difusión de las políticas nacionales para el campo educativo en general y para la formación de profesores en particular. Se mostrará cómo la racionalidad técnica se manifiesta el campo de la educación y como esa intervención se ha ido acelerando e intensificando en los últimos años. Se reafirmará la importancia de entender el presente con vistas a fomentar maneras de enfrentamiento y resistencia al proyecto social neoliberal implementado hoy en día.

PALABRAS CLAVE: Educación. La racionalidad burguesa. Resistencia. Humanización.

\section{NOTA}

1 - A LDB 9.394/96, em resposta ao expressivo contingente de professores leigos que atuam na educação básica, em seu artigo 62, define o nível superior como formação mínima exigida para o ingresso no magistério nas séries iniciais e estabelece o período de dez anos para aplicação desta determinação. A transferência do locus da formação em nível superior, Resolução CNE/CP n. 01/1999, retira da universidade a responsabilidade pela formação de professores e transfere-a para os Institutos Superiores de Educação/ISEs. O Decreto presidencial n. 3.276/1999 define que essa formação ocorreria exclusivamente nos ISEs. Em resposta ao movimento de resistência realizado 
pelas entidades científicas do campo da educação, o governo Fernando Henrique Cardoso, por meio do Decreto presidencial n. 3.554/2000 altera a orientação legal substituindo o termo "exclusivamente" por "preferencialmente".

\section{REFERÊNCIAS}

ADORNO, T. W. Educação e Emancipação. Tradução Wolfgang Leo Maar. Rio de Janeiro: Paz e Terra, 1995.

ADORNO, T. W.; HORKHEIMER, M. Dialética do esclarecimento: fragmentos filosóficos. 2 ed. Rio de Janeiro: Zahar, 1991.

AGUIAR, M. A. S. Institutos Superiores de Educação na nova LDB. In: BRZEZINSKI, I. (org.) LDB Interpretada: diversos olhares se entrecruzam. São Paulo: Cortez, 1997.

AGUIAR, M. A. S; DOUURTADO, L. F. (Orgs.). A BNCC na contramão do PNE 2014-2024: avaliação e perspectivas. [livro eletrônico] - Recife: ANPAE, 2018.

ANTUNES, R. Coronavírus: o trabalho sob fogo cruzado. $1^{\text {a }}$ ed. São Paulo: Boitempo, 2020.

ANTUNES, R. O privilégio da servidão: o novo proletariado de serviços na era digital. São Paulo: Boitempo, 2018.

ANTUNES, R. Os sentidos do trabalho: ensaios sobre a afirmação e a negação do trabalho. São Paulo: Boitempo, 2001.

BOLLMANN, M. da G. LDB Comentada. ADUFG, 1997.

BRANDÃO, C. R. O que é educação. 21. ed. São Paulo: Brasiliense, 1988.

BRASIL, Ministério da Educação - Secretaria de Educação Básica. BASE NACIONAL COMUM CURRICULAR; educação é base. 2017.

BRZEZINSKI, I. (org.). A formação e a carreira de professor da educação na LDB 9.394/96: possibilidades e perplexidades. I: BRZEZINSKI, I. (org.) LDB Interpretada: diversos olhares se entrecruzam. São Paulo: Cortez, 1997.

BRZEZINSKI, I. Embates na definição das políticas de formação de professores para a atuação multidisciplinar nos anos iniciais do Ensino Fundamental: Respeito à cidadania ou disputa pelo poder? In:Educação e Sociedade. Formação de Profissionais da Educação: Políticas e tendências. CEDES, nº 68, 1999. 
BARCELOS, S. M. V.

CASTRO, M. H. G; CALLOU, R. (Org.). Educação em pauta: uma agenda para o país. Athalaia Gráfica e Editora, 2018.

CURY, C. R. J. Legislação educacional brasileira. Rio de Janeiro: DP ed., 2000.

DARDOT, P.; LAVAL, C. A nova razão do mundo: ensaio sobre a sociedade neoliberal. São Paulo, Boitempo, 2016.

DELORS, J. (org). Educação: Um tesouro a descobrir. São Paulo: Cortez; Brasília: MEC/UNESCO, 1998.

DE TOMMASI, E. et al. (orgs.) O Banco Mundial e as políticas educacionais. São Paulo: Cortez; Ação Educativa e PUC/SP, 1996.

EVANGELISTA, E. G. dos S. A Unesco e o mundo da cultura. Goiânia: Ed. da UFG, 1999.

EVANGELISTA, E. G. dos S. Educação e mundialização. Goiânia, Editora da UFG, 1997.

FRIGOTTO, G. Os circuitos da história e o balanço da educação no Brasil na primeira década do século XXI. Revista Brasileira de Educação - v.16, n 46 jan-abr, p. 235-274.

FRIGOTTO, G. Educação, Crise do Trabalho Assalariado e do Desenvolvimento: Teorias em Conflito. In: Educação e Crise do Trabalho: Perspectiva de Final de Século. Petrópolis: Vozes, 1999.

GENTILI, P. Neoliberalismo, qualidade total e educação, visões críticas. Petrópolis, RJ: Vozes, 1995.

GRAMSCl, A. Concepção dialética da história. Rio de Janeiro: Civilização Brasileira, 1985.

GRAMSCI, A. Os intelectuais e a organização da cultura. Rio de Janeiro: Civilização Brasileira, 1978.

HARVEY, D. O neoliberalismo: história e implicações. ão Paulo, Loyola, 2008.

HORKHEIMER, M. Eclipse da razaão. São Uchoa Leite, Editoria Labor do Brasil, Rio de Janeiro, 1976.

HYPOLITO, A. M. BNCC, agenda globas e formação docente. Revista Retratos da Escola. Brasília, v.13, n.25, p. 187-201, jan./mai., 2019.

IANNI, O. Capitalismo, violência e terrorismo. Rio de Janeiro, Civilização Brasileira, 2004. 
MELO, M. T. L. Programas oficiais para formação dos professores da educação básica. In: Educação e Sociedade. Formação de Profissionais da Educação: Políticas e tendências. CEDES, nº 68, 1999.

MÉSZAROS, I. A educação para além do capital. São Paulo: Boitempo, 2005.

MIRANDA, M. G. Crise na educação: a retórica conservadora. Retratos da escola. Brasília v. 10 n. 19, p. 567-579, jul/dez 2016. Disponível em:

http://retratosdaescola.emnuvens.com.br/rde/article/view/700. Acesso em: 07 dez. 2019.

TORRES, Ros a Maria. Educação para todos: A tarefa por fazer. Trad. Daisy Moraes. Porto Alegre: Artmed, 2001.

TOSCHI, M. S. LDB Comentada. ADUFG, 1997.

Simone de Magalhães Vieira Barcelos: Doutora em Educação, Mestre em Educação e Graduada em Pedagogia pela Universidade Federal de Goiás nos anos de: 2017, 2004 e 1991 respectivamente. Professora efetiva/DE da Universidade Estadual de Goiás com atuação desde 2010 na área de Fundamentos da Educação.

Orcid: https://orcid.org/0000-0002-6763-621X

E-mail: vieirabarcelos@hotmail.com

Este periódico utiliza a licença Creative Commons Attribution 3.0, para periódicos de acesso aberto (Open Archives Initiative - OAI). 